Vegetalika. 2017. 6(2): 55-65

\title{
Uji Daya Hasil dan Kualitas Buah Tujuh Hibrida Tomat (Solanum Lycopersicum L.) di Dataran Rendah
}

\section{Yield Potence and Fruit Quality Seven Hybrid of Tomato (Solanum Lycopersicum L.) in Low Land}

\author{
Widya Rachmatika1), Rudi Hari Murti2²), Panjisakti Basunanda²) \\ 1) Program Studi Pemuliaan Tanaman, Fakultas Pertanian, Universitas Gadjah Mada \\ 2) Departemen Budidaya Pertanian, Fakultas Pertanian, Universitas Gadjah Mada \\ ") Penulis untuk korespodensi E-mail: rhmurti@ugm.ac.id
}

\begin{abstract}
This research aimed to identify of hybrid with high yield also high quality fruit tomatoes to determine the best crosses GM lines with CLN4046. Genotypes parents consisted of 'Gamato 1' (A131), 'Gamato 2' (A65), 'Gamato 3' (A134), 'Gamato 4' (A175), 'Gamato 5'(B52), and CLN4046. Check variety consist of 'Kaliurang', 'Betavila', dan 'Servo'. This experiment had been conducted in Jambeyan, Karanganom, Klaten and in the laboratory of Plant Breeding and Horticulture, Department of Agronomy, Faculty of Agriculture, University of Gadjah Mada in April-August 2015. The hybrids and check variety arranged in a complete randomized block design (RCBD) with 3 blocks are replications. Each experimental unit consisted of ten plants, and three plants as sample. Hybrid result from crossing GM lines with CLN4046 consisted of 'Gamato 1' $x$ CLN4046, 'Gamato 2' $\times$ CLN4046, 'Gamato 3' × CLN4046, CLN4046 × Gamato3, 'Gamato 4' × CLN4046, CLN4046 × 'Gamato 4', and 'Gamato 5' x CLN4046'. Selected hybrid based on heterosis and potence ratio. Selected hybrid based heterosis in superiority of quality fruits in low land was 'Gamato 4' × CLN4046 71,35 Newton and 'Gamato 5' × CLN4046 67,40 Newton by means potence ratio overdominance positive. Hybrid by means high productivity in low land based heterosis showed in hybrid 'Gamato 4' $\times$ CLN4046 39,93 ton/ha. Positive correlation showed in weight fruit per plant $(r=0,959)$ toward productivity. Path analysis showed directly effect more than indirectly effect in weight fruit per plant $(0,965)$. Fruit quality seven hybrid did not showed indirectly effect in significant toward life storage.
\end{abstract}

Keyword: yield, quality fruits, hybrid, correlation, path analysis.

\section{INTISARI}

Penelitian ini bertujuan mendapatkan hibrida untuk dataran rendah dengan daya hasil tinggi serta kualitas buah yang baik dari hasil persilangan tomat seri GM dengan CLN4046. Galur tetua yang digunakan antara lain 'Gamato 1' (A131), 'Gamato 2' (A65), 'Gamato 3' (A134), 'Gamato 4' (A175), 'Gamato 5'(B52), dan CLN4046. Pembanding yang digunakan dalam penelitian ini ialah 'Kaliurang', 'Betavila', dan 'Servo'. Penelitian dilakukan di kebun percobaan Jambeyan, Karanganom, Klaten, serta dilakukan di 
Laboratorium Pemuliaan Tanaman dan Laboratorium Hortikultura, Departemen Agronomi, Fakultas Pertanian. Penelitian dilaksanakan pada bulan April-Agustus 2015. Penelitian ini menggunakan Rancangan Acak Kelompok Lengkap (RAKL) dengan faktor tunggal berupa macam nomor persilangan berupa tiga blok unit percobaan sebagai ulangan. Masingmasing unit blok terdiri dari sepuluh tanaman dengan tiga tanaman sebagai sampel. Hibrida hasil persilangan tomat seri GM dengan CLN4046 yaitu, 'Gamato 1' $\times$ CLN4046, 'Gamato 2' × CLN4046, 'Gamato 3' × CLN4046, CLN4046 × Gamato 3', 'Gamato 4' × CLN4046, CLN4046 × 'Gamato 4', dan 'Gamato 5' × CLN4046. Pemilihan hibrida dilakukan berdasarkan efek heterosis dan nisbah potensi. Hibrida terpilih berdasarkan keunggulan heterosis dengan kualitas kekerasan buah yang baik pada dataran rendah ditunjukkan pada hibrida 'Gamato 4' x CLN4046 sebesar 71,35 Newton dan 'Gamato 5' × CLN4046 sebesar 67,40 Newton dengan nisbah potensi dominansi berlebih positif. Hibrida dengan produktivitas tinggi untuk dataran rendah berdasarkan nilai heterosis paling baik ditunjukkan pada hibrida 'Gamato 4' × CLN4046 dengan produktivitas 39,93 ton/ha. Hubungan korelasi bernilai positif bobot buah per tanaman $(r=0,959)$ terhadap produktivitas. Path analisis menunjukkan pengaruh langsung lebih besar dari pengaruh tidak langsung pada komponen hasil bobot buah per tanaman $(0,965)$. Komponen kualitas buah tujuh hibrida menunjukkan tidak ada pengaruh langsung secara signifikan terhadap daya simpan.

Kata kunci: daya hasil, kualitas buah, hibrida, korelasi, path analisis.

\section{PENDAHULUAN}

Menurut data Badan Pusat Statistik dan Direktorat Jendral Hortikultura luas panen tomat di Indonesia tahun 2011 sampai 2015 mengalami penurunan sebesar 7,57 \%. Penurunan luas panen tomat tersebut berdampak pada penurunan produksi nasional sekitar 4,07 \%, namun hasilnya mengalami kenaikan sebesar 3,65\%. Tanaman tomat umumnya dibudidayakan di dataran tinggi. Tanaman yang dibudidayakan di dataran tinggi lebih produktif dari pada di dataran rendah. Namun, pengembangan budidaya tanaman tomat di dataran tinggi dinilai dapat memicu terjadinya erosi tanah, di samping itu ketersediaan lahan terbatas. Oleh karena itu, perluasan areal untuk budidaya tanaman tomat lebih diarahkan ke dataran rendah. Salah satu penyebab rendahnya produktivitas tanaman tomat di dataran rendah adalah belum adanya berdaya hasil tinggi dengan kualitas benih bermutu yang sesuai dengan agroklimat dataran rendah (Imam et al., 2015).

Berbagai permasalahan yang dihadapi dalam meningkatkan produksi dengan kualitas buah yang baik sangat sulit dicapai. Tanaman tomat saat ini mengalami stagnansi rata-rata per hektar sulit sekali dikembangkan dan ditingkatkan produktivitasnya (Prabowo, 2008). Selain sulitnya mendapatkan produksi tinggi, kualitas buah tomat juga menjadi 
Widya Rachmatika et al., / Vegetalika. 2017. 6(2): 55-65

pertimbangan dalam peningkatan kualitas mutu buah tomat. Kriteria buah tomat dengan kualitas yang baik memiliki sifat seperti kekerasan buah yang baik, kandungan vitamin dan mineral yang cukup, serta memiliki daya simpan yang baik pula. Buah tomat memiliki variasi kandungan kimia yang berbeda setiap jenis buah tomat. Oleh karena itu menjaga mutu produk buah tomat sangat penting. Mutu produk hortikultura sangat dipengaruhi oleh cara penanganan pascapanennya. Mutu produk dapat dipertahankan dengan penanganan lanjutan yang cepat dan tepat. Tomat tergolong sayuran buah (fruit-type vegetabel) yang bersifat mudah rusak (perishable) (Hartuti, 2006). Salah satu mutu produk hortikultura yang sangat penting dipertahankan ialah kekerasan buah. Kekerasan buah merupakan sifat yang dimiliki produk hortikultura seperti tebalnya kulit maupun lapisan lilin yang menentukan tingkat daya simpan.

Penelitian ini dilakukan untuk mendapatkan hibrida dengan sifat keras pada buah tomat dari hasil persilangan yang ada. Perbaikan sifat kekerasan buah tomat dilakukan dengan cara menyilangkan galur murni yang memiliki sifat unggul jumlah buah yang banyak pada buah keras (CLN4046) dengan enam galur murni 'Gamato 1' (A131), 'Gamato 2' (A65), 'Gamato 3' (A134), 'Gamato 4' (A175) dan 'Gamato 5' (B52). Kelima galur murni tersebut merupakan hasil persilangan dari tomat seri GM yaitu galur GM2 dan 'Gondol'. Kelima galur murni tersebut memiliki sifat unggul buah yang berukuran besar, berdaging tebal dan air buahnya banyak, namun buah mudah pecah serta kulit buah tidak keras. Tomat CLN4046 merupakan salah satu koleksi dari BALITSA Bandung, yang memiliki keunggulan kulit buah keras. Hasil persilangan antara CLN4046 dengan enam galur murni tersebut diharapkan mampu menghasilkan buah yang besar dan memiliki tingkat kekerasan yang baik (Jayanti, 2015). Hasil persilangan tersebut juga dibandingan dengan kultivar komersial untuk mengetahui hibrida tersebut layak dipasarkan. Penelitian ini menggunakan tiga kultivar pembanding 'Kaliurang', 'Servo' dan 'Betavila' untuk mengevaluasi kualitas buah tomat serta produktivitas hasil persilangan antara seri GM dengan CLN4046.

\section{BAHAN DAN METODE}

Penelitian dilaksanakan pada bulan April-Agustus 2015. Penelitian dilakukan di lahan di Desa Jambeyan, Karanganom, Klaten dengan ketinggian tempat $400 \mathrm{~m}$ dpl (dataran rendah). Penelitian laboratorium dilakukan di Laboratorium Pemuliaan Tanaman 
dan Laboratorium Hortikultura, Departemen Agronomi, Fakultas Pertanian. Tanaman tomat yang digunakan dalam penelitian meliputi bahan tanam tomat dari tujuh nomor tetua dan tujuh hasil persilangan dengan CLN4046 (Tabel 1). Bahan lain yang dibutuhkan antara lain pupuk kandang, pupuk anorganik berupa pupuk NPK, Urea, KCl, dan SP-36; pestisida, mulsa plastik hitam perak, tali rafia, kapur dolomit, plastik, kertas label, ajir bambu, larutan IKI 0,001 N, larutan $\mathrm{NaOH} \mathrm{0,1} \mathrm{N,} \mathrm{Amilum} \mathrm{1 \% ,} \mathrm{Indikator} \mathrm{phenolphalin} \mathrm{(PP),}$ dan akuades. Peralatan yang digunakan adalah cangkul, gembor, penggaris atau meteran, pisau, gunting, timbangan elektronik "AND GF 6100" buatan Jepang dengan kapasitas $6100 \mathrm{~g}$ dan minimum dapat dibaca 0,01 g, refraktometer "ATAGO" A-01-37 buatan Jepang berskala 0-32\% Brix, chromameter tipe "Konica dan Mlnota" CR-400 buatan Jepang, penetrometer "Barreiss Prufgeratebau" GmbH tipe BS 61 II/BS 61 II OO" seri 2553, jangka sorong, buret, gelas ukur, gelas beker, erlenmeyer, dan alat tulis.

Data pengamatan yang diperoleh dianalisis menggunakan analisis varian dan nilai varian genetiknya diduga dengan metode yang disusun dalam Rancangan Acak Kelompok Lengkap (RAKL) faktor tunggal. Jika terdapat berbeda nyata antar perlakuan, maka dilakukan uji lanjut berupa uji Beda Nyata Jujur (BNJ) atau Honest Significant Difference (HSD) taraf kepercayaan 5\% (Singh dan Chaudhary, 1979). Analisis ini menggunakan SAS 9.1. Pemilihan hibrida terbaik berdasarkan nilai heterosis, heterobeltiosis, standar heterosis, dan nisbah potensi. Pemilihan hibrida tersebut juga dilihat berdasarkan nilai korelasi dan pangeruh langsung dan tidak langsung dengan path analisis pada setiap komponen karakter tujuh hibrida.

\section{HASIL DAN PEMBAHASAN}

Tujuh hibrida dari hasil persilangan tersebut menghasilkan penampilan baru yang berbeda dari tetuanya. Penampilan karakter hibrida tersebut dapat diamati melalui karakter jumlah buah per tandan, persentase pembentukan buah, jumlah tandan per tanaman, bobot buah per butir, bobot buah per tandan, bobot buah per tanaman, produktivitas, komposisi kimiawi buah, ukuran buah, bentuk buah, jumlah, jumlah lokul, tebal daging, kekerasan buah, dan daya simpan. Berdasarkan karakter penampilan hibrida tersebut tindak gen tujuh hibrida terhadap tetuanya dapat diketahui.

Komponen hasil pada tujuh hibrida dan tetua ditampilkan pada Tabel 1. Jumlah buah per tandan pada ketujuh hibrida berkisar antara 3,85-5,19. Jumlah buah per tandan 
Widya Rachmatika et al., / Vegetalika. 2017. 6(2): 55-65

paling banyak ditunjukkan pada hibrida CLN4046 × 'Gamato 4' sebanyak 5,56. Jumlah buah per tandan paling sedikit ditunjukkan pada hibrida 'Gamato 5' × CLN4046 sebanyak 3,85. Rerata pembentukan buah paling tinggi ditunjukkan pada hibrida CLN4046 $\times$ 'Gamato 4' (79,99\%).

Karakter pembentukan buah pada 'Gamato 3' × CLN4046 menunjukkan penampilan lebih baik dari rerata kedua tetua sebesar $35,30 \%$. Hal tersebut juga ditunjukkan pada hibrida CLN4046 × 'Gamato 4 sebesar 23,08\%. Keunggulan hibrida tersebut kurang lengkap bila penampilan karakter pembentukan buah tersebut tidak lebih baik dari kultivar pembanding seperti yang ditunjukkan pada hibrida 'Gamato 3' $\times$ CLN4046. Hibrida 'Gamato 3' × CLN4046 menunjukkan jumlah tandan per tanaman paling besar diantara ketiga hibrida lain. Karakter jumlah tandan per tanaman pada hibrida 'Gamato 3' × CLN4046 memiliki fenotipe lebih baik dari rerata kedua tetuanya pada nilai heterosis sebesar $18,92 \%$ dan lebih baik terhadap rerata kultivar pembanding yang ditunjukkan pada nilai heterosis standan sebesar 15,79.

Bobot buah per tandan pada tujuh hibrida berkisar antara 208,36-546,38 gram. Hibrida CLN4046 × 'Gamato 4' memiliki bobot buah per tandan paling besar sebesar 546,38 gram. Hibrida CLN4046 × 'Gamato 4' berbeda nyata dengan kedua tetua 'Gamato 4' dan kultivar pembanding 'Betavila'. Karakter bobot buah per tandan pada hibrida CLN4046 × 'Gamato 4' dan resiproknya tidak berbeda nyata dengan hibrida 'Gamato 1' $\times$ CLN4046 dan 'Gamato 2' × CLN4046. Keempat hibrida tersebut juga tidak berbeda nyata dengan bobot buah per tandan pada kultivar pembanding 'Kaliurang' dan 'Servo'. 
Widya Rachmatika et al., / Vegetalika. 2017. 6(2): 55-65

Tabel 1. Komponen hasil tujuh hibrida tomat dan tetua

\begin{tabular}{|c|c|c|c|c|c|c|c|}
\hline Galur/kultivar & JBPT & PB (\%) & JTPTN & $\begin{array}{l}\text { BBPB } \\
\text { (gram) }\end{array}$ & $\begin{array}{l}\text { BBPT } \\
\text { (gram) }\end{array}$ & $\begin{array}{c}\text { BBPTN } \\
\text { (gram) }\end{array}$ & $\begin{array}{c}\mathrm{PD} \\
\text { (ton/ha) }\end{array}$ \\
\hline 'Kaliurang' & 5,03 a-d & $70,38 a b$ & $3,89 a b$ & $68,04 a b$ & $465,67 a b$ & $2,07 a-c$ & $34,61 \mathrm{a}-\mathrm{c}$ \\
\hline 'Betavila' & $5,85 a b$ & 80,03 a & $4,33 \mathrm{ab}$ & 60,07 a-c & $271,75 \mathrm{bc}$ & 2,84 a-c & 47,45 a-c \\
\hline 'Servo’' & $6,67 \mathrm{a}$ & $81,42 \mathrm{a}$ & $5,44 \mathrm{a}$ & $51,35 \mathrm{bc}$ & 288,09 a-c & $2,65 a-c$ & $44,25 a-c$ \\
\hline CLN4046 & $5,30 \mathrm{a}-\mathrm{c}$ & $74,29 a b$ & $5,33 \mathrm{a}$ & $31,71 \mathrm{c}$ & 340,31 a-c & $4,19 \mathrm{a}$ & 69,85 a \\
\hline 'Gamato 1' (A131) & $3,28 c-e$ & $57,14 a b$ & $3,89 a b$ & $72,00 \mathrm{ab}$ & $312,87 \mathrm{a}-\mathrm{c}$ & $2,31 \mathrm{a}-\mathrm{c}$ & 38,54 a-c \\
\hline 'Gamato 2' (A65)' & $4,01 \mathrm{~b}-\mathrm{e}$ & $59,64 a b$ & $3,78 \mathrm{ab}$ & $50,41 \mathrm{bc}$ & $253,65 \mathrm{bc}$ & $1,66 \mathrm{bc}$ & 27,67 bc \\
\hline 'Gamato 3’ (A134) & $3,79 \mathrm{~b}-\mathrm{e}$ & 39,76 b & $2,89 \mathrm{~b}$ & $60,04 a-c$ & $170,03 \mathrm{c}$ & $1,25 \mathrm{bc}$ & $20,80 \mathrm{bc}$ \\
\hline 'Gamato 4’ (A175) & $3,77 \mathrm{~b}-\mathrm{e}$ & $55,69 a b$ & $3,88 a b$ & $61,97 \mathrm{a}-\mathrm{c}$ & $164,72 \mathrm{c}$ & $3,47 a b$ & $57,85 a b$ \\
\hline 'Gamato 5' (B52) & $2,91 \mathrm{de}$ & $60,16 a b$ & $3,67 a b$ & 57,76 a-c & $262,16 \mathrm{bc}$ & $0,91 \mathrm{c}$ & $15,23 \mathrm{c}$ \\
\hline 'Gamato 1' × CLN4046 & $4,44 \mathrm{~b}-\mathrm{e}$ & $73,50 \mathrm{ab}$ & $4,11 a b$ & $61,95 \mathrm{a}-\mathrm{c}$ & 330,08 a-c & $0,81 \mathrm{c}$ & $13,60 \mathrm{c}$ \\
\hline 'Gamato 2' × CLN4046 & $4,01 \mathrm{~b}-\mathrm{e}$ & $78,74 \mathrm{a}$ & $4,67 a b$ & 54,19 bc & 291,18 a-c & $0,62 \mathrm{c}$ & $10,42 \mathrm{c}$ \\
\hline 'Gamato 3' × CLN4046 & 5,08 a-d & $77,15 \mathrm{a}$ & $4,89 \mathrm{a}$ & $70,55 \mathrm{ab}$ & $272,00 \mathrm{bc}$ & 2,12 a-c & 35,33 a-c \\
\hline CLN4046 × 'Gamato 3' & $5,19 a-c$ & $71,75 a b$ & $4,55 a b$ & $92,25 \mathrm{a}$ & $447,79 \mathrm{ab}$ & $1,01 \mathrm{c}$ & $16,93 \mathrm{bc}$ \\
\hline 'Gamato 4’ × CLN4046 & 5,07 a-d & $73,57 \mathrm{ab}$ & $4,55 \mathrm{ab}$ & $63,50 \mathrm{a}-\mathrm{c}$ & $392,23 a-c$ & $2,40 \mathrm{a}-\mathrm{c}$ & 39,93 a-c \\
\hline CLN4046 × 'Gamato 4' & $5,56 a b$ & 79,99 a & $4,88 \mathrm{a}$ & $56,95 \mathrm{bc}$ & $546,38 \mathrm{a}$ & $0,88 \mathrm{c}$ & $14,76 \mathrm{bc}$ \\
\hline 'Gamato 5’ × CLN4046 & $3,85 \mathrm{~b}-\mathrm{e}$ & $65,21 a b$ & $3,55 a b$ & 59,65 a-c & 208,36 b-c & $0,88 \mathrm{c}$ & $14,76 \mathrm{c}$ \\
\hline $\mathrm{CV}(\%)$ & 15,45 & 16,46 & 15,23 & 18,73 & 27,87 & 39,59 & 41,98 \\
\hline
\end{tabular}

Keterangan: Angka dalam kolom yang diikuti huruf yang sama menunjukkan tidak berbeda nyata menurut uji jarak HSD pada tingkat kepercayaan $5 \%$. CV = Coefficient of variation JBPT : Jumlah Buah pert Tandan, PB: Pembentukan Buah, JTPTN: Jumlah Tandan per Tanaman, BBPB: Bobot Buah per Butir, BBPT: Bobot Buah per Tandan, BBPTN: Bobot Buah Per Tanaman, PD: Produktivitas. 
Widya Rachmatika et al., / Vegetalika. 2017. 6(2): 55-65

Komponen hasil yang menentukan bobot total hasil meliputi jumlah tandan bunga, jumlah bunga per tandan, kemampuan bunga membentuk buah (fruit set), jumlah buah per tanaman, dan bobot per buah (Komardiputri, 2010). Produktivitas suatu komoditas dapat ditentukan oleh beberapa komponen diantaranya ialah bobot buah per butir. Hibrida dengan bobot buah per tanaman paling besar ditunjukkan pada hibrida 'Gamato 3' × CLN4046 (2,12 kg) dan 'Gamato 4' x CLN4046 (2,40 kg). Hibrida dengan produktivitas produktivitas kurang dari CLN4046 (69,85 ton/ha) antara lain hibrida 'Gamato 1' $\times$ CLN4046 (13,60 ton/ha), 'Gamato 2' × CLN4046 (10,42 ton/ha), CLN4046 × 'Gamato 3' (16,93 ton/ha), CLN4046 × 'Gamato 4' (14,76 ton/ha) dan 'Gamato 5' × CLN4046 (14,76 ton/ha). Kelima hibrida tersebut menunjukkan penampilan produktivitas lebih rendah dari tetua CLN4046

Nilai kekerasan buah pada hibrida ditunjukkan pada galur 'Gamato 4' × CLN4046 sebesar 71,35 Newton dan paling rendah ditunjukkan pada hibrida 'Gamato 3' × CLN4046 sebesar 57,05 Newton (Tabel 2). Kekerasan kulit buah ditentukan oleh beberapa faktor. Menurut Nasution et al, (2012) kekerasan buah yang tinggi bisa disebabkan karena tekstur buah yang sudah layu, sedangkan nilai kekerasan buah yang rendah dapat disebabkan karena buah telah busuk. Hal tersebut sependapat dengan Lamona et al, (2015) mengatakan bahwa nilai kekerasan tinggi mengindikasikan terjadinya kekeringan pada buah. Hal tersebut disebabkan oleh besaran nilai kehilangan air dari buah yang menyebabkan buah menjadi layu dan keriput dan menyebabkan tekstur menjadi lebih keras.

Karakter jumlah lokul pada tujuh hibrida berkisar antara 1,45 sampai 1,79. Jumlah lokul paling banyak ditunjukkan pada hibrida 'Gamato 1' $\times$ CLN4046 dan 'Gamato 5' × CLN4046 dengan jumlah 1,79. Jumlah lokul paling sedikit ditunjukkan pada hibrida 'Gamato 2' × CLN4046 dengan jumlah 1,45. Menurut Damayanti (2006) cit. Komardiputri (2010) jumlah rongga biji menentukan tingkat kekerasan buah. Buah tomat dengan jumlah rongga biji yang banyak, tingkat kekerasan buah cenderung tinggi. Hal ini karena dengan jumlah rongga biji yang banyak, volume rongga terbagi menjadi banyak ruang dan menyebabkan dinding buah serta sekat antar ruang manjadi tebal sehingga buah menjadi keras. Semakin banyak rongga biji, buah tomat akan semakin keras sehingga dalam proses pengangkutan dan pengepakan tidak mudah rusak, namun biji akan dihasilkan juga semakin banyak. 
Tebal daging paling besar ditunjukkan pada hibrida CLN4046x'Gamato 3' sebesar 7,42 mm. Tebal daging paling tipis ditunjukkan pada hibrida 'Gamato 1' × CLN4046 sebesar 5,46 mm. Daya simpan pada tujuh hibrida memiliki umur simpan selama 13,15 hari sampai 26,24 hari. Daya simpan paling lama ditunjukkan pada hibrida 'Gamato 1 ' $\times$ CLN4046 selama 26,24 hari. Daya simpan paling cepat daya simpan pada hibrida 'Gamato 5' × CLN4046 selama 13,15 hari.

Komposisi kandungan Padatan Terlarut Total pada tujuh hibrida berkisar 4,01 $\mathrm{B}$ Brix sampai 5,41 Brix. Menurut Nasution et al, (2012) total asam merupakan energi tambahan pada buah yang diperkirakan banyak menurun selama aktivitas metabolisme berlangsung. Rerata kandungan Total Asam Terlarut tujuh hibrida berkisar antara 0,17\%-0,23\%. Kandungn Total Asam Teralrut tertinggi ditunjukkan pada hibrida CLN4046 × 'Gamato 4' sebesar $0,23 \%$. Ketujuh hibrida di atas (Tabel 2) memiliki kandungan vitamin $\mathrm{C}$ yang hampir sama. Kandungan vitamin C paling tinggi ditunjukkan oleh hibrida CLN4046 $\times$ 'Gamato 4' sebesar 46,44 mg. Kandungan vitamin C paling rendah ditunjukkan oleh 'Gamato 2' × CLN4046 sebesar 33,98 mg. Menurut Nasution et al, (2012) penurunan kandungan vitamin $\mathrm{C}$ dapat dipengaruhi oleh proses respirasi dan transpirasi yang menyebabkan menurunnya kadar air buah.

Karakter panjang buah menentukan bentuk buah. Panjang buah paling besar ditunjukkan pada hibrida CLN4046 × 'Gamato 3' sebesar 57,78 mm, sedangkan paling rendah ditunjukkan pada hibrida 'Gamato 1' $\times$ CLN4046 48,62 mm. Hibrida yang memiliki diameter paling besar ditunjukkan pada galur 'Gamato 5' $\times$ CLN4046 sebesar 49,40 mm, sedangkan paling kecil ditunjukkan pada hibrida 'Gamato 3' $\times$ CLN4046 sebesar 41,55 $\mathrm{mm}$. Diameter buah menentukan bentuk buah pada masing-masing hibrida.

Penggolongan bentuk buah menunjukkan berbagai bentuk buah tomat. Hibrida 'Gamato 1' × CLN4046, 'Gamato 2' × CLN4046, 'Gamato 4' × CLN4046 dan resiproknya menunjukkan bentuk buah bulat. Bentuk buah lonjong ditunjukkan hibrida 'Gamato 3' $\times$ CLN4046 dan resipronya menyerupai bentuk buah kedua tetua. Hibrida 'Gamato 5' $\times$ CLN4046 memiliki bentuk buah apel. 
Widya Rachmatika et al., / Vegetalika. 2017. 6(2): 55-65

Tabel 2. Kualitas buah tujuh hibrida dan tetuanya.

\begin{tabular}{|c|c|c|c|c|c|c|c|}
\hline \multirow{2}{*}{ Galur/kultivar } & \multirow{2}{*}{$\begin{array}{c}\text { KB } \\
\text { (Newton) }\end{array}$} & \multirow{2}{*}{ JL } & \multirow{2}{*}{ TD } & \multirow{2}{*}{ DS } & \multicolumn{3}{|c|}{ Kandungan kimia buah } \\
\hline & & & & & PTT & $\mathrm{AT}$ & Vitamin C \\
\hline 'Kaliurang' & $61,51 \mathrm{a}-\mathrm{c}$ & $2,04 \mathrm{a}$ & $4,91 \mathrm{a}-\mathrm{c}$ & $23,30 \mathrm{a}-\mathrm{d}$ & $4,69 \mathrm{~b}$ & $0,20 \mathrm{~b}$ & $38,62 a b$ \\
\hline 'Betavila' & $75,61 \mathrm{a}$ & $1,45 \mathrm{a}$ & $5,60 \mathrm{a}-\mathrm{c}$ & $14,18 b-d$ & $3,23 b$ & $0,12 b$ & $38,13 a b$ \\
\hline 'Servo’ & $67,81 \mathrm{a}-\mathrm{c}$ & $1,45 \mathrm{a}$ & 4,69 a-c & $12,11 \mathrm{~cd}$ & $5,24 \mathrm{~b}$ & $0,18 \mathrm{~b}$ & $49,87 \mathrm{ab}$ \\
\hline CLN4046 & 66,31 a-c & $1,45 \mathrm{a}$ & $4,84 \mathrm{a}-\mathrm{c}$ & 25,63 a-d & $4,54 a b$ & $0,19 b$ & $43,76 a b$ \\
\hline 'Gamato 1' (A131) & $41,61 \mathrm{a}-\mathrm{c}$ & $1,46 \mathrm{a}$ & $3,52 \mathrm{c}$ & $10,56 \mathrm{~d}$ & $3,27 \mathrm{~b}$ & $0,19 b$ & $25,91 \mathrm{~b}$ \\
\hline 'Gamato 2’ (A65) & $74,24 a b$ & $1,79 \mathrm{a}$ & 4,55 a-c & $34,22 \mathrm{a}$ & $6,36 a b$ & $0,24 b$ & $36,67 a b$ \\
\hline 'Gamato 3’ (A134) & 67,95 a-c & $1,73 \mathrm{a}$ & $3,91 \mathrm{bc}$ & $29,71 \mathrm{a}-\mathrm{c}$ & $8,60 \mathrm{a}$ & $0,40 \mathrm{a}$ & $52,80 \mathrm{a}$ \\
\hline 'Gamato 4’ (A175) & 67,81 a-c & $1,79 \mathrm{a}$ & 5,33 a-c & 22,74 a-d & $5,47 a b$ & $0,20 \mathrm{~b}$ & 56,96 a \\
\hline 'Gamato 5' (B52) & $58,64 \mathrm{bc}$ & $1,79 \mathrm{a}$ & $5,84 a-c$ & $30,67 \mathrm{ab}$ & $5,31 a b$ & $0,23 b$ & $43,02 a b$ \\
\hline 'Gamato 1' × CLN4046 & 63,99 a-c & $1,79 \mathrm{a}$ & 5,46 a-c & $26,24 a b$ & $5,41 a b$ & $0,17 b$ & $40,57 \mathrm{ab}$ \\
\hline 'Gamato 2’ × CLN4046 & $67,73 \mathrm{a}-\mathrm{c}$ & $1,45 \mathrm{a}$ & $6,81 \mathrm{ab}$ & 23,78 a-d & $4,32 \mathrm{~b}$ & $0,17 \mathrm{~b}$ & $33,97 \mathrm{ab}$ \\
\hline 'Gamato 3’ × CLN4046 & $57,52 \mathrm{c}$ & $1,59 \mathrm{a}$ & $6,56 a b$ & $17,67 \mathrm{a}-\mathrm{d}$ & $4,35 \mathrm{~b}$ & $0,21 b$ & $40,57 \mathrm{ab}$ \\
\hline CLN4046 × 'Gamato 3' & 62,42 a-c & $1,59 \mathrm{a}$ & $7,42 \mathrm{a}$ & 24,22 a-d & $4,01 \mathrm{~b}$ & $0,17 b$ & $36,57 \mathrm{ab}$ \\
\hline 'Gamato 4’ × CLN4046 & 71,35 a-c & $1,63 \mathrm{a}$ & $6,76 \mathrm{ab}$ & 21,76 a-d & $4,09 \mathrm{~b}$ & $0,17 b$ & $37,64 a b$ \\
\hline CLN4046 × 'Gamato 4' & 66,95 a-c & $1,55 \mathrm{a}$ & $6,12 \mathrm{a}-\mathrm{c}$ & 24,52 a-d & $4,42 \mathrm{~b}$ & $0,23 b$ & $46,44 a b$ \\
\hline 'Gamato 5’ × CLN4046 & 67,40 a-c & $1,79 \mathrm{a}$ & $6,05 \mathrm{a}-\mathrm{c}$ & $13,15 b-d$ & $4,72 \mathrm{~b}$ & $0,18 b$ & $38,37 \mathrm{ab}$ \\
\hline $\mathrm{CV}(\%)$ & 8,29 & 11,24 & 17,43 & 18,43 & 22,72 & 25,80 & 20,66 \\
\hline
\end{tabular}

Keterangan: Angka dalam kolom yang diikuti huruf yang sama menunjukkan tidak berbeda nyata menurut uji jarak HSD pada tingkat kepercayaan 5\%. CV = Coefficient of variation. KB: Kekerasan Buah, P: Panjang Buah, D: Diameter, JL: Jumlah Lokul, TD: Tebal Daging, DS: Daya Simpan, PTT: Padatan Terlarut Total, AT: Asam Tertitrasi. 
Tabel 3. Bentuk buah tujuh hibrida dan tetua berdasarkan nisbah P:D

\begin{tabular}{|c|c|c|c|c|}
\hline Galur/kultivar & $\begin{array}{c}\text { Panjang buah } \\
(\mathrm{mm})\end{array}$ & $\begin{array}{c}\text { Diameter buah } \\
(\mathrm{mm})\end{array}$ & $\begin{array}{c}\text { Nisbah P:D } \\
(\mathrm{mm})\end{array}$ & $\begin{array}{c}\text { Bentuk } \\
\text { Buah }\end{array}$ \\
\hline 'Kaliurang' & $48,08 \mathrm{a}$ & $51,27 \mathrm{a}$ & $0,95 a b$ & apel \\
\hline 'Betavila' & $49,21 \mathrm{a}$ & $43,79 a$ & $1,13 a b$ & bulat \\
\hline 'Servo’' & $49,10 \mathrm{a}$ & $43,70 \mathrm{a}$ & $1,12 a b$ & bulat \\
\hline CLN4046 & $50,94 a$ & $34,79 a$ & $1,46 \mathrm{a}$ & lonjong \\
\hline 'Gamato 1' (A131) & $37,71 \mathrm{a}$ & $35,87 \mathrm{a}$ & $0,70 \mathrm{~b}$ & apel \\
\hline 'Gamato 2' (A65) & $59,18 a$ & $47,39 \mathrm{a}$ & $1,25 a b$ & lonjong \\
\hline 'Gamato 3' (A134) & $51,18 \mathrm{a}$ & $42,18 \mathrm{a}$ & $1,21 a b$ & lonjong \\
\hline 'Gamato 4' (A175) & $60,81 \mathrm{a}$ & $46,17 \mathrm{a}$ & $1,32 \mathrm{a}$ & lonjong \\
\hline 'Gamato 5' (B52) & $54,81 \mathrm{a}$ & $49,17 \mathrm{a}$ & $1,11 a b$ & bulat \\
\hline 'Gamato 1' × CLN4046 & $48,62 \mathrm{a}$ & $42,11 \mathrm{a}$ & $1,18 a b$ & bulat \\
\hline 'Gamato 2' × CLN4046 & 53,66 a & $44,79 \mathrm{a}$ & $1,20 a b$ & bulat \\
\hline 'Gamato 3' × CLN4046 & $53,12 a$ & $41,55 \mathrm{a}$ & $1,28 \mathrm{a}$ & lonjong \\
\hline CLN4046 × 'Gamato 3' & $57,78 \mathrm{a}$ & $44,99 \mathrm{a}$ & $1,28 \mathrm{a}$ & lonjong \\
\hline 'Gamato 4' × CLN4046 & $54,41 \mathrm{a}$ & $46,56 \mathrm{a}$ & $1,17 a b$ & bulat \\
\hline CLN4046 × 'Gamato 4' & $51,88 \mathrm{a}$ & $41,67 \mathrm{a}$ & $1,24 a b$ & bulat \\
\hline 'Gamato 5' × CLN4046 & 49,51 a & 49,40 a & $1,00 a b$ & apel \\
\hline $\mathrm{CV}(\%)$ & 16,43 & 18,99 & 15,62 & \\
\hline
\end{tabular}

\section{KESIMPULAN}

1. Produktivitas paling besar ditunjukkan pada Hibrida 'Gamato 3' $\times$ CLN4046 dan 'Gamato 4' × CLN4046 masing-masing sebesar 35,33 ton/ha dan 39,93 ton/ha.

2. Hibrida 'Gamato 1' $\times$ CLN4046 dan CLN4046 × 'Gamato 4' menunjukkan kualitas paling baik yang ditunjukkan pada setiap karakter pengamatan.

\section{SARAN}

1. Hibrida 'Gamato 3' $\times$ CLN4046 dan 'Gamato 4' $\times$ CLN4046 berpeluang sebagai kultivar unggul yang adaptif di dataran rendah.

2. Produktivitas tujuh hibrida masih jauh dari kultivar pembanding kecuali 'Gamato 3' × CLN4046 dan 'Gamato 4' × CLN4046, sehingga perlu dilakukan perbaikan sifat dengan persilangan galur yang adaptif di dataran rendah.

3. Hibrida CLN4046 × 'Gamato 4' memiliki penampilan kualitas buah baik serta berpotensi produksi tinggi. 
Widya Rachmatika et al., / Vegetalika. 2017. 6(2): 55-65

\section{DAFTAR PUSTAKA}

Anonim,2014. Prospek budidaya tomat. <http://www.petanihebat.com/2014/05/prospekbudidaya-tomat.html>, Diakses 20 Oktober 2016.

Hartuti, N. 2006. Penanganan segar pada penyimpanan tomat dengan pelapian lilin untuk memperpanjang masa simpan. IPTEK Hortikultura No.2. Balai Penelitian Tanaman Sayuran, Bandung.

Imam, K., Murniati., dan Deviona. 2015. Keragaan delapan genotipe tanaman tomat (Lycopersicum esculentum Mill.) di dataran rendah. Jom Faperta. 2:1-8.

Jayanti, T.D. 2015. Evaluasi mutu dan daya simpan buah tomat (Solanum lycopersicum L.) hasil persilangan seri gm dengan cln4046 generasi f1. Skripsi. Fakultas Pertanian. Universitas Gadjah Mada.

Komardiputri, P. 2010. Keragaan agronomis galur tomat (Lycopersicum esculentum Mill.) generasi 6 hasil irradiasi sinar gamma co-60 di dataran rendah. Skripsi. Fakultas Pertanian. UGM.

Lamona, A., Y.A. Purwanto., dan Sutrisno. 2015. Pengaruh janis kemasan dan penyimpanan suhu rendah teradap perubahan kualitas cabai merah keriting segar. Jurnal Keteknikan Pertanian. 3: 145-152.

Nasution, I.S., Yusmanizar, dan K. Melianda. 2012. Pengaruh penggunaan lapisan edibel (edible coating), kalsium klorida, dan kemasan plastik terhadap mutu nanas (Ananas comosus Merr.) terolah minimal. Jurnal Teknologi dan Industri Pertanian Indonesia. 4:21-26.

Prabowo,R.2008. Kajian biopestisida dan pupuk hayati dalam mndujung pengelolaan tanaman tomat secara terpadu. Medisagra. 4: 81-88.

Singh, R.K. and B.D. Chaudhary. 1979. Biometrical methods in quantitative genetic analysis. Ludhiana: Kalyani. 